\title{
Coal-gas interaction: implications of changes in texture and porosity
}

\author{
Vyacheslav N. Romanov $^{1} \cdot$ Lauren C. Graeser $^{1} \cdot$ Sinisha A. Jikich $^{1} \cdot$ Yee Soong $^{1} \cdot$ Gino A. Irdi $^{1}$
}

Received: 19 January 2015/Revised: 15 May 2015/Accepted: 27 August 2015/Published online: 11 December 2015

(C) The Author(s) 2015. This article is published with open access at Springerlink.com

\begin{abstract}
Transient sorption and desorption of helium and carbon dioxide in Upper Freeport coal powder and lumps were analyzed. Differences in texture and porosity between the powder and lumps may affect the transport and interaction of the penetrant and coal. In this work, we address macroscopic and mesoscopic structural differences between powdered and non-powdered coals that influence the rates of the gas transport kinetics and changes in coal texture (swelling, shrinkage, and changes in the pore structure and interconnectivity) and the reciprocal free-phase pressure decay (relaxation). Comparison of the multi-exponential relaxation time constants as a function of pressure, for $\mathrm{CO}_{2}$ and inert gas (helium), allows us to postulate several mechanisms responsible for observed pressure decay patterns.
\end{abstract}

Keywords Coal $\cdot$ Gas $\cdot$ Porosity $\cdot$ Structure $\cdot$ Diffusion $\cdot$ Sorption $\cdot$ Swelling

\section{Introduction}

Coal is an abundant sedimentary rock commonly associated with energy, primarily used as a solid fuel to produce electricity and heat. Significant research efforts were directed toward development of coal liquefaction, especially, in Germany, South Africa, and China (Wasaka et al. 2002). However, the state-of-the-art in coal-based energy conversion technologies is not adequate in the current regulatory environment concerned with potential environmental crisis. If the known methods were adopted industrywide to reduce oil consumption, carbon dioxide emission could increase on a global scale (Romanov et al. 2009). On the other hand, deep unmineable coal seams may find use as the reservoirs for sequestration of 'green house' gases. Interaction of $\mathrm{CO}_{2}$ with coal, which is occasionally referred to as heterogeneous geo-polymer in nature (Marzec 2002) is governed by the aggregate properties of the two

Vyacheslav N. Romanov

romanov@netl.doe.gov

1 U. S. Department of Energy, National Energy Technology Laboratory, P. O. Box 10940, Pittsburgh 15236, USA substances. The $\mathrm{CO}_{2}$ molecules may adsorb at microporous surfaces of coal and form a condensed liquid-like layer; they can also dissolve into cross-linked coal matrix, resulting in coal structural rearrangement (swelling/ shrinkage) and, possibly, even glass-to-rubber transition (Romanov 2007). Under the reservoir conditions, freephase $\mathrm{CO}_{2}$ may undergo a transition to supercritical phase, with an intriguing mix of properties attributable to gas and liquid substances.

Potential for storage of anthropogenic carbon dioxide $\left(\mathrm{CO}_{2}\right)$ in natural coals is typically evaluated by conducting sorption isotherm studies on crushed and pulverized coal powder to reduce the time to reach equilibrium (Ozdemir 2004; Romanov and Soong 2009). When such data is used for modeling the $\mathrm{CO}_{2}$ transport and storage in coal, the results can be misleading, if the model does not take into account the differences in texture and porosity between coal powder and lumps (Romanov and Soong 2008) that may affect the interaction of fluids and coal (Romanov and Soong 2009). Adequate representation of the internal structure of the coal in place is necessary for successful modeling of the interactions and transport processes subsequent to $\mathrm{CO}_{2}$ injection into geological formations (Bhatia 1987). The permeability of coal seams to $\mathrm{CO}_{2}$ is crucial to sequestration of $\mathrm{CO}_{2}$ in 
deep coal seams. Similarly, the permeability is crucial to production of methane from coal seams (Li et al. 2012; Yang et al. 2012; Nie et al. 2014a, b). It involves both Darcy flow through cleats and cracks and diffusion through the coal (Ryan and Mannhardt 2007). This study is concerned primarily with processes associated with diffusion of gases in coal. Transport processes in microporous solids are governed by bulk diffusion, Knudsen diffusion, or surface diffusion depending on feature size, shape and geometric arrangement of pores and characteristic matrix blocks (Bhatia 1987; Siemons et al. 2004; Romanov and Soong 2009). Conventional models of gas transport in coal account only for diffusion through interconnected pore network believed to exist in all coals (Mahajan 1991). Alternatively, it has been argued that, typically, the majority of pores in coal are isolated and many internal surfaces cannot be reached by diffusion through a pore network (Alexeev et al. 1999). Rather, transport through the solid macromolecular coal is analogous to diffusion through non-porous polymers (Hall et al. 1992; Romanov 2007). In the pores of molecular dimensions, interaction forces strongly depend on kinetic diameter and geometry of diffusing species, closeness of approach between the pseudo-graphitic basal planes, and chemical nature of the coal region (not so prominently in high-carbon coals); polarizable molecules may have a better ability to penetrate between the coal lamellae due to stronger specific interaction (dipole-dipole or hydrogen bonding) with coal constituents (Nandi and Walker 1970). As we prepare to analyze the experimental data for pressure relaxation in response to coal-gas interaction during the sorption isotherm measurements, we will catalog the most popular hypothesis and their corollary effects on the relaxation rates.

In Sect. 4 (Results and discussion), the temporal data for helium and $\mathrm{CO}_{2}$ transport and interaction processes are assimilated in lumps and powder of the Argonne Premium Coal samples of Upper Freeport medium volatile bituminous coal. $\mathrm{CO}_{2}$ is routinely used to measure coal surface area. Typically, in such measurements, it is assumed that the probing gas does not affect the coal properties. The comparison of the $\mathrm{CO}_{2}$ transport and interaction behavior with that of helium will be used to more accurately characterize the mechanisms of gas transport and gas-coal interaction and determine if there are any changes occurring in coal structure.

\section{Theory}

In the following theoretical discussion, only unsteady-state gas transport into and out of a spherical particle is considered. Since the rates of such processes are relatively insensitive to particle's shape (Ryan and Mannhardt 2007) the effective radius $\mathrm{R}$ will simply represent corresponding volume of the actual particle or transport grain size. To simplify the mathematics of the coal-gas systems under study, we will assume that at each pressure step the freephase gas concentration is maintained constant. This assumption may result in overestimation of diffusivities of the species for a given particle size (using the experimentally observed pressure relaxation as a measure of the gas uptake) but it should not affect our general conclusions about factors governing the rates of the processes. Under the above assumptions, we will consider several basic models of gas interchange between free phase and a system of isomorphous spherical coal particles. The models will be ranked according to the rate-determining process.

(1) Case I-R ( $\mathrm{R}$ stands for spherical geometry): In a classic approach, when the temporal rate of reaching the equilibrium pressure across the entire system is determined by thermally activated (low activation energies) motion of diffusing species, Fick's diffusion equation is assumed to be applicable. For $\mathrm{CO}_{2}$, the analytical solutions should be interpreted in terms of the 'occluded gas' model (Walker et al. 1966) for total (including sorbed phase) concentration gradient as we intend to compare them to experimental data. However, for relatively small concentration gradients created at each pressure step, we can still use the 'sorption-free gas' model with the effective diffusion coefficient $\theta$ :

$\theta=\frac{D}{\phi+H_{\mathrm{p}}}$

where $D$ is the true diffusion coefficient (independent of pressure), $\phi$ is the open (interconnected) porosity, and $H_{\mathrm{p}}$ is the effective (uniform pressure approximation) Henry's law parameter for incremental sorption. One more caveat we need to consider is that the unipore diffusion equation is not very accurate in describing the final stages ('tail') of the pressure relaxation process. A bi-disperse model or two-component unipore equation, for a sample composed of vitrinite with slow diffusivity and inertinite with faster diffusivity, produce a much better fit (Ryan and Mannhardt 2007). It is expected that for the Upper Freeport coal, with $91 \%$ vitrinite and only $8 \%$ inertinite (Vorres 1993), the 'tail' diffusion kinetics will be controlled by vitrinite. The analytical solution for the residual fraction of the Fickian diffusion process is (Marecka and Mianowski 1998):

$$
y=\frac{V_{\mathrm{f}}-V(t)}{V_{\mathrm{f}}-V_{\mathrm{i}}}=\frac{6}{\pi^{2}} \sum_{n=1}^{\infty} \frac{\exp \left(-\frac{n^{2}}{R^{2}} s D t\right)}{n^{2}}
$$

where $V_{\mathrm{i}}, V(t)$ and $V_{\mathrm{f}}$ are the free-phase equivalent volumes evolved at time $0, t$ and $\infty$ respectively, $s$ is 
the shape parameter $\left(s=\pi^{2}\right.$ for a sphere). For practical purposes, this equation can be approximated (within $5 \%$ error) by the following empirical formula:

$y \approx 0.8 \times \exp \left(-\frac{t}{0.7 \tau}\right)+0.18 \times \exp \left(-\frac{35 t}{\tau}\right)$

For $\varepsilon>0.1$ and the $y$-values between $\varepsilon$ and $(1-\varepsilon)$, the first exponential term in this equation matches the precise equation with correlation of $r^{2} \sim 1$, which yields the rate constant $\left(\tau=R^{2} /(s D)\right)$ values within $5 \%$ of the actual. Stability of the best-fit rate constant, with respect to arbitrary selection of $\varepsilon$, provides a valuable opportunity to use the Eq. (3) for multi-exponential rate analysis of the experimental data. Swelling (Case IV-R) caused by surface tension due to adsorption can slightly convolute the observed pressure changes.

(2) Case II-R: This kind of transport is characterized by osmotically-induced strain relaxation (Romanov 2007) which propagates with a constant velocity $u$ toward the center of the particle (Hall et al. 1992). It is assumed that the rate of pressure equilibration in interconnected pores is much faster than the rate of mass uptake into macromolecular network, because the rate-determining step of imbibition is the motion of the coal macromolecules. If the sharp concentration-gradient front propagation is slow enough compared to the Fickian diffusion through the relaxed portion of the coal matrix, the mass uptake (proportional to the relaxed volume) obeys a simple cubic law and the equivalent (for a typical exponential fit, $\varepsilon>0.1$ ) pressure relaxation time constant $\tau$, which is now proportional to $R$, is determined by the following equation:

$y(\tau)=(1-u \tau / R)^{3} \approx \frac{1.2}{e}$

Swelling due to imbibition will convolute the observed pressure changes.

(3) Case III-R: Diffusion is limited by purely mechanical response of the coal matter to gas pressure or stresses induced by gas sorption. In addition to interconnected pores implied in Case I-R study, coal matrix is believed to have finer and, possibly, isolated (blind) pores, which arise from turbostratic packing of the fundamental building blocks (Ozdemir 2004). When the gas pressure in micropores reaches a certain threshold, it may start moving apart coal building blocks, allowing the gas to enter into blind (initially, not interconnected) pores (Moffat and Weale 1955; Nelson et al. 1980) or, possibly, removing a monolayer of sorbed organic species and water blocking some voids of molecular dimensions (Walker et al. 1988a). If the characteristic time constant of these subtle changes in coal texture is very large, the associated decrease in observed freephase pressure will follow on the heels of the Case I-R diffusion process; the two-component unipore equation is a more adequate fit for such complex diffusion:

$y=\frac{6}{\pi^{2}} \sum_{n=1}^{\infty} \frac{d \exp \left(-\frac{n^{2}}{R^{2}} s^{\prime} D t\right)+(1-d) \exp \left(-\frac{n^{2}}{\tau^{\prime \prime}} \frac{t}{1+t / \tau^{\prime}}\right)}{n^{2}}$

where $d$ is a distribution factor defining proportions of the two components, $s^{\prime}$ is a modified shape factor, and $\tau^{\prime}$ and $\tau^{\prime \prime}$ are the respective time constants controlling the onset and duration of the mechanical response.

(4) Case IV-R: After detectable penetrant transport into the coal particle is complete, the free-phase pressure may continue to change because of the volumetric effects (Romanov et al. 2006a). Large local pressure gradients (up to $100 \mathrm{MPa}$ ) due to surface tension induced by adsorption may cause appreciable deformations but typically do not produce large volumetric changes (Walker et al. 1988a). On the other hand, chemical interaction of the fluid with coal, such as imbibition, can result in large swelling. The initial (for the mixing ratio $\phi_{2} \rightarrow \phi_{2}^{*}$, with $*$ corresponding to the onset of coal plasticization) relaxation of strain $\varepsilon$ is driven by the lowering of activation energy of the glass-to-rubber transition in coal matrix via mechanical work performed by the penetrating gas (Romanov 2007):

$\varepsilon=\frac{\Delta \pi_{2}}{K^{*}}\left(1-e^{-\frac{K^{*}}{\eta_{2}} t}\right)+\varepsilon\left(\phi_{2}^{*}\right) e^{-\frac{K^{*}}{\eta_{2}} t}$

where $\phi_{2}$ is the volume fraction of the network in the mixed phase, $\eta_{2}$ is its viscosity, $\Delta \pi_{2}$ is the swelling pressure induced by imbibition of the penetrant, and $K^{*}$ is the bulk modulus of the swelling region (Osmotic bulk modulus $K^{*}$ can be different from the $K$ value defining the rate constant $\tau^{\prime \prime}$ in the Case III$\mathrm{R})$. This transition state provides the macromolecular network more freedom of chain motion, which allows it to rearrange to a more stable conformation. Using dual-energy X-ray computed tomography (Xray CT), (Karacan 2003) has observed that certain microlithotypes of confined Pittsburgh seam coal, at pressures 1.7-4.4 MPa, showed a decreasing trend in the bulk density for $\sim 40 \mathrm{~h}$, after which there was a period of slight density increase at each pressure step. Karacan (2003) drew analogy with $\mathrm{CO}_{2}$ 
injectivity behavior observed at the Allison Unit of San Juan Basin (Reeves 2003)-initial significant decline in injectivity was followed by a long period of improvement-implying that overburden pressure may eventually force $\mathrm{CO}_{2}$ out of coal matrix, after the system rearranged to a more stable state with reduced solubility (Karacan 2007) and the related swelling pressure $\Delta \pi_{2}$. In our experiments, swelling or shrinking of coal matrix, with the corresponding changes in void volume, results in free-phase pressure relaxation. The induced changes in pressure may become partly offset by adjustment in the amount of gas uptake, either because it is not near saturation or because coal porosity is affected by confining stress (Walker et al. 1988b). The latter should not significantly affect the rates of associated pressure relaxation, which are independent of the particle size in this case, unlike Case II-R; differentiation between the two cases is either because of undetectable imbibition causing detectable volumetric effects or because of relatively small (much smaller than the particle size) matrix blocks that can be reached by the penetrant without appreciable imbibition.

(5) Case V-R: Good solvents, including supercritical $\mathrm{CO}_{2}$ may extract water and/or non-cross-linked volatile matter $(\mathrm{VM})$ from coal, resulting in changes in void volume (Romanov et al. 2006a, b) and in equation-of-state of the free phase (Romanov 2007). The fraction of the $\mathrm{CO}_{2}$ surface area covered by water may reach $73 \%$ in lignite; in general, it ranges $15 \%$ $25 \%$ in vitrinite (Walker et al. 1988a). In an unlikely case of rapid complete dissolution of the VM, diffusion of the solute out of the particle can be described by the model similar to Case I-R diffusion. In the case of very slow dissolution (for the most mature coals, such as Pocahontas and Upper Freeport) and relatively faster transport, the solute concentration is low and its gradient is a linear function of the particle radius (Appendix A); the solute outflow matches the maximum VM dissolution rate for the in situ solvent activity and does not change over time until all VM is dissolved. The intermediate case of extraction under the saturation conditions results in constant rate of cross-diffusion of the solute and solvent. Extraction of the volatile matter will not be considered in this work as we analyze the results of experiments on dry Upper Freeport medium volatile bituminous coal interacting with inert helium (at room temperature, $\sim 7 \mathrm{MPa}$ ) and gaseous $\mathrm{CO}_{2}$ (at $55^{\circ} \mathrm{C},<5.5 \mathrm{MPa}$ ) at relatively low temperatures and pressures. Analysis of the supercritical $\mathrm{CO}_{2}$ interaction with coal is beyond the scope of this study.

\section{Materials and methods}

Experimental data are reported for time dependence of $\mathrm{CO}_{2}$ sorption in powder and lumps samples of Upper Freeport coal. Sample preparation procedures such as grinding and outgassing can affect the measured physical properties of coal (Walker et al. 1988a). Some description of the samples and experimental setup used for sorption measurements can be found elsewhere (Romanov and Soong 2009). Here, for convenience, the most important information is summarized and additional details relevant for the subject of this study are provided. The powder (particle size $<75 \mu \mathrm{m}$; as received $13.987 \mathrm{~g})$ and lumps $(1.7 \mathrm{~cm} \times$ $1.4 \mathrm{~cm} \times 3.2 \mathrm{~cm}, \quad 1.7 \mathrm{~cm} \times 1.7 \mathrm{~cm} \times 2.9 \mathrm{~cm}$; total $21.928 \mathrm{~g}$ ) were pressed into confining containers (Fig. 1) and dried in vacuum at $80^{\circ} \mathrm{C}$ for $36 \mathrm{~h}$.

Mineral composition of the lump pieces was identified via the local density and effective atomic number, which were reduced from the data collected with the dual-energy (sources: $80 \mathrm{kV}$ for photoelectric absorption and $140 \mathrm{kV}$ for Compton scattering) CT-scanner (Model HD-350E, Universal Systems, Inc., Solon, OH, USA). The non-destructive computed tomography (CT) scanning was done incrementally, by $0.2 \mathrm{~cm}$ steps (slices), with enhanced lateral spatial resolution of $<0.025 \mathrm{~cm}$. Data processing and visualization were performed using Matlab 7.0, according to the routine outlined elsewhere (Siddiqui and Khamees 2004). Properties of coal depend on its density (van Krevelen 1993). The selected coal lumps are very heterogeneous, with the local density ranging 0.9-4.2 g/ $\mathrm{cm}^{3}$ (Fig. 2), but the average density of a combination of the two lumps matches the density of representative Argonne Premium Coal powder. According to the color map (located to the right of the images) the top sample had a significant number of mineral inclusions (bright spots, with the average density in excess of $2 \mathrm{~g} / \mathrm{cm}^{3}$ ), while the sample at the bottom appeared to be a typical coal maceral matter.

The X-ray diffraction (XRD) spectra (Fig. 3), collected using a multi-purpose diffractometer, X'Pert PRO MPD (PANalytical, B.V., Almelo, The Netherlands) indicates that both powder and lump samples are the mostly amorphous mix of organic and phyllosilicate matter, with the powder having larger amounts of the products of clay weathering (Table 1). According to the CT data, minerals ( $Z_{\text {eff }}>11$ ) may comprise up to $26 \%$ of the total lumps' mass.

Effective atomic number, $Z_{\text {eff }}$, readings show that the lower lump (lump 2) was composed of predominantly carbonaceous coal macerals (mostly, vitrinite group macerals with the density $\left.(1.35 \pm 0.1) \mathrm{g} / \mathrm{cm}^{3}\right), Z_{\text {eff }}<10$, while the upper lump (lump 1) was mineral-rich, with significant 

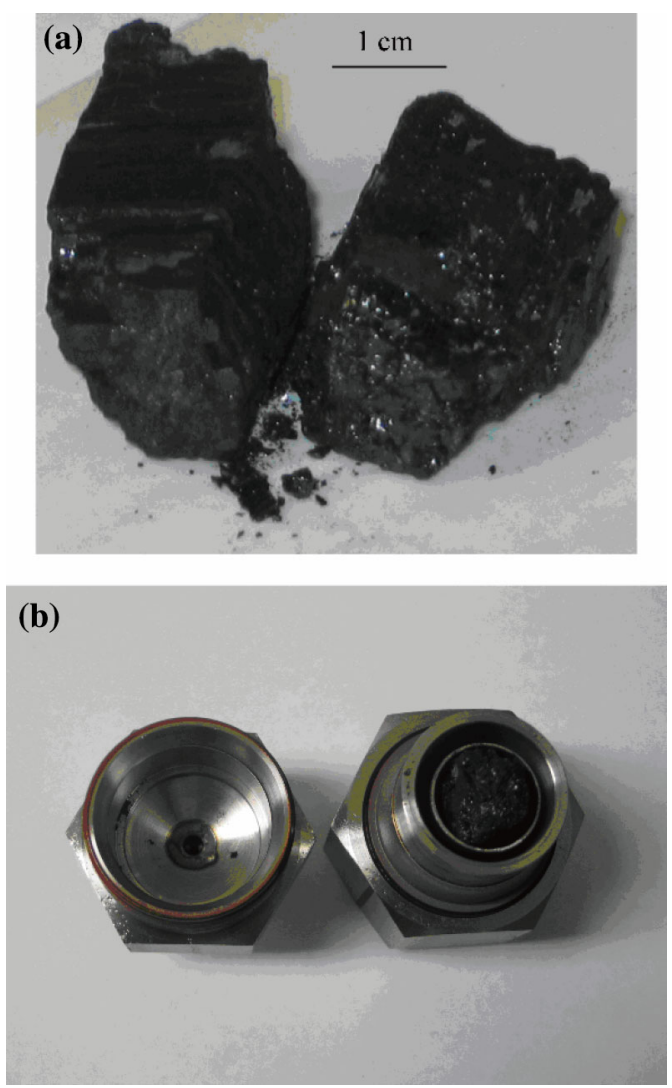

Fig. 1 Photos. a Two lumps before being placed into pressure vessel; b Two lumps inside of a confining container

amount of calcite inclusion, $Z_{\text {eff }}>16$ (Fig. 4). The vitrinite peak density in the lump 1 was shifted to $(1.45 \pm 0.1)$ $\mathrm{g} / \mathrm{cm}^{3}$, with two distinct shoulders, one, very narrow, at $(1.35 \pm 0.1) \mathrm{g} / \mathrm{cm}^{3}$ (a relatively purer vitrinite) and one, much broader ( $\sim 10 \%$ of the total lumps' volume), at $(1.75 \pm 0.1) \mathrm{g} / \mathrm{cm}^{3}\left(Z_{\text {eff }}<11\right)$. Although the effective atomic number readings are not very accurate due to difficulties with the low-energy calibration, they provide some qualitative indication that the latter is due to a presence of higher density maceral form. The relatively purer vitrinite's density in both lumps appears to be the same, $\sim 1.35 \mathrm{~g} /$ $\mathrm{cm}^{3}$, which is slightly higher but within error bars of $\sim 1.3 \mathrm{~g} / \mathrm{cm}^{3}$ that was reported by (van Krevelen 1993) for vitrinite of a similar chemical composition. With sufficiently good accuracy, the sample composition can be described as well-dispersed mixture of macerals (representative density $1.3-1.4 \mathrm{~g} / \mathrm{cm}^{3}$ ) and minerals (representative density $2.7 \mathrm{~g} / \mathrm{cm}^{3}$ ). In such representation, average density reflects the weight ratio of minerals (predominantly, clay) and macerals (predominantly, vitrinite).

The micro- and meso-porosity of coal samples were estimated using the BET, BJH and Dubinin-Astakhov analyses of the sorption isotherms at Micromeritics Analytical Services, Norcross, GA, USA (Table 2). The

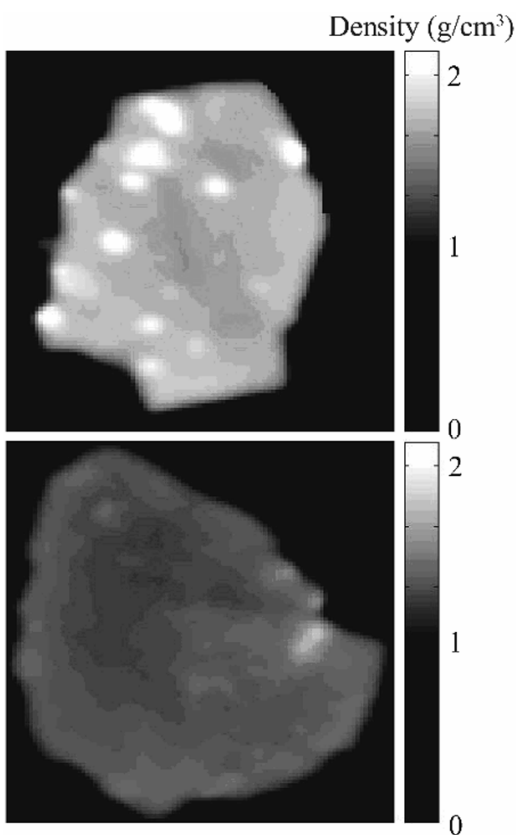

Fig. 2 CT-density images of the top (the second slice from the top of the upper, mineral-rich sample) and the bottom (the second slice from the bottom of the lower, organics-rich sample) slices (area: $2.5 \mathrm{~cm} \times 2.5 \mathrm{~cm}$ ). The thickness of one 'slice' is $0.2 \mathrm{~cm}$. The dark background (zero density) is the area outside of the samples

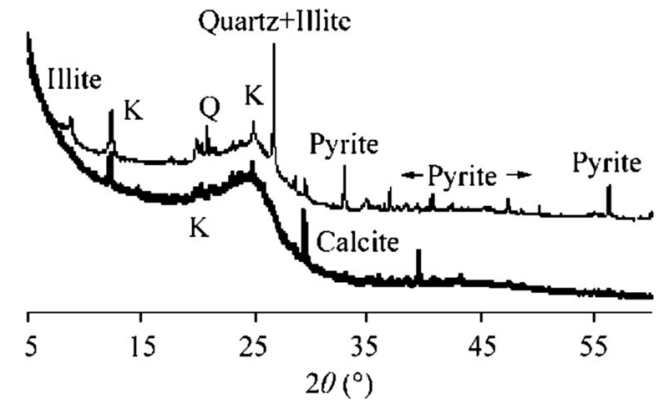

Fig. 3 X-ray diffraction spectra of coal powder (top) and lump flakes (bottom)

Table 1 Structural composition of Argonne Premium Upper Freeport coal samples: XRD analysis versus analytical data by Argonne National Laboratory (Vorres 1993)

\begin{tabular}{lrc}
\hline Compound & XRD $(\%)$ & Argonne $(\%)$ \\
\hline Amorphous & $\sim 81.0$ & 84.7 \\
Calcite & 1.0 & 1.0 \\
Clay & 12.0 & $<9.4$ \\
Pyrite & 3.5 & 3.4 \\
Quartz & 2.5 & 1.5 \\
\hline
\end{tabular}

characteristic energy of the $\mathrm{CO}_{2}$ sorption was $(24.25 \pm 0.19) \mathrm{kJ} / \mathrm{mol}$ for the powder and $(19.76 \pm 0.57)$ $\mathrm{kJ} / \mathrm{mol}$ for the lumps (Romanov and Soong 2009). 

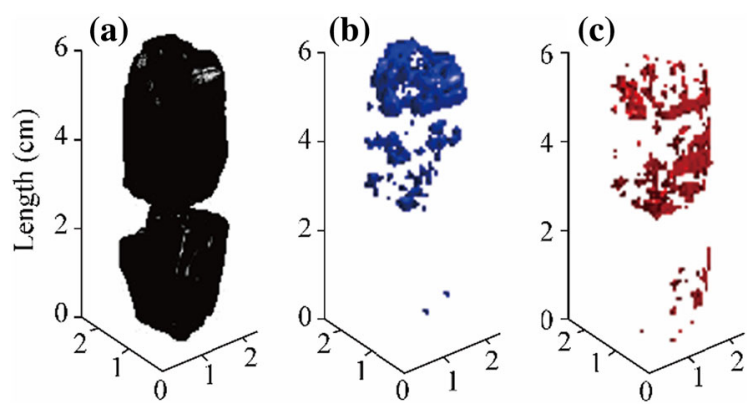

Fig. 4 CT-image (scale: 1 inch $\sim 2.5 \mathrm{~cm}$ ) of the coal lumps' composition. a Sample; b Clay inclusions; c Calcite inclusions

For sorption studies, we used the NETL-built manometric apparatus (Romanov and Soong 2008, 2009) to collect the helium (99.997\% purity, Valley Co., Pittsburgh, PA, USA) transport data at room temperature and then $\mathrm{CO}_{2}$ (99.999\% purity, Valley Co., Pittsburgh, PA, USA) sorption isotherm at $(55.00 \pm 0.01){ }^{\circ} \mathrm{C}$. The duration of the pressure equilibration steps ranged from one to three weeks. In addition, multiple 'helium-volume' measurements with 5 to 15 min equilibrium time were made at the pressures of $1.5 \mathrm{MPa}$ to $7 \mathrm{MPa}$.

\section{Results and discussion}

Here we compare the experimental data for helium and $\mathrm{CO}_{2}$ transport and interaction processes in the same samples, lumps and powder, of the Upper Freeport coal. The average pore size in Upper Freeport coal is $(0.63 \pm 0.07)$ $\mathrm{nm}$ (Hayashi et al. 2001), which is slightly larger than the typical size $(<0.58 \mathrm{~nm})$ corresponding to onset of activated diffusion in coal (Walker 1981). Since gas transport in larger pores is very rapid, the experimentally observed pressure relaxation over extended period of time is diffusion in smallest pores (ultra-micropores).

Previously, it has been reported (Romanov and Soong 2009) that helium penetration into the dry coal matrix results in slow relaxation of pressure, which was attributed to gas penetration into coal matrix controlled by microscopic changes in pore space accessibility. The relaxation time on first exposure to helium was 3-4 days, regardless of the macroscopic dimensions of the sample. Then it decreased for the lumps with each subsequent exposure.

Table 2 Porosity (\% volume) of the coal samples (Romanov and Soong 2009)

\begin{tabular}{llll}
\hline Pores & Powder & Upper lump & Lower lump \\
\hline Micropores & 4.44 & 5.36 & 5.72 \\
Mesopores & 0.99 & 0.04 & $0.02-0.08$ \\
\hline
\end{tabular}

The desorption process was more rapid than preceding sorption, for all samples. Evolution of the sorption-desorption rates indicated that exposure to helium may change the texture and apparent density of dry coal (Romanov and Soong 2009). Each time after exposure to helium, the 'helium volume' of the lumps irreversibly increased due to improved accessibility of the sorption sites, but there were no significant changes of the macroscopic dimensions of coal. The total pressure drop during the relaxation was always smaller for the lumps than for the powder.

Multi-exponential fitting (Enderlein and Erdmann 1997) of the helium sorption-desorption decay process indicated that it could be a combination of several sub-processes characterized by different rates. The slower portion ('tail') of helium sorption on lumps was characterized by decrease in the rate of pressure relaxation $(1 / \tau)$. As part of this transition, the faster portion of the pressure drop had gradually increased and the slower portion had decreased in magnitude. It was suggested (Romanov and Soong 2009) that the changes in slower helium uptake processes are related to rearrangements in the micropore structure, which are irreversible for the coal lumps; whereas the relaxation time constant $\tau$ is associated with characteristic length $R$ of microscopic blocks of the coal matrix separated by regular micro cracks (Romanov 2007). Unlike sorption, helium desorption off the powder sample was bimodal, while desorption off the lumps, after the third sorption-desorption cycle, was not (Romanov and Soong 2009). Such pressure relaxation behavior is attributed to a combination of Case I-R (faster) and Case III-R (initially, slower) processes, because helium is inert gas.

It is interesting to see whether transport of a different gas molecule in the coal trained by the repeated pre-exposure to high pressure $(\sim 7 \mathrm{MPa})$ helium will result in additional changes in coal structure. $\mathrm{CO}_{2}$ sorption measurements have been done in pressure steps $\sim 1 \mathrm{MPa}$ up to pressure $\sim 14 \mathrm{MPa}$ (Romanov and Soong 2008). Here we report pressure relaxation behavior only for $\mathrm{CO}_{2}$ gas because of increasing relative errors associated with the equation-of-state for supercritical $\mathrm{CO}_{2}$ before it reaches complete thermodynamic equilibrium. Multi-exponential fitting of the $\mathrm{CO}_{2}$-induced sorption decay curves was used to distinguish between the instant (1-2 min), initial and final ('tail') relaxation steps (Table 3). The contribution of the instant adsorption on the 'open' (accessible via larger pores) surface areas, initial activated diffusion-limited (Case I-R) sorption, and final relaxation were estimated as the percentage of the total (equilibrium) excess sorption increments.

Striking resemblance between the relaxation rate constants of $\mathrm{CO}_{2}$ sorption in lumps and powder implies independence of the underlying processes from the apparent particle size. The bi-exponential function was not always 
Table $3 \mathrm{CO}_{2}$ sorption kinetics on coal powder

\begin{tabular}{|c|c|c|c|c|c|c|}
\hline \multirow[t]{2}{*}{ Pressure (MPa) } & \multicolumn{2}{|c|}{ Instant equilibrium } & \multicolumn{2}{|c|}{ Initial relaxation } & \multicolumn{2}{|c|}{ Final relaxation } \\
\hline & $\tau_{0}(\mathrm{~h})$ & Magnitude (\%) & $\tau_{\mathrm{i}}(\mathrm{h})$ & Magnitude (\%) & $\tau_{\mathrm{f}}(\mathrm{h})$ & Magnitude (\%) \\
\hline 0.4 & 0.03 & 53 & 0.08 & 45 & 12.2 & 2 \\
\hline 1.2 & 0.03 & 11 & 0.08 & 84 & 23.0 & 5 \\
\hline 1.9 & 0.03 & 69 & 0.09 & 64 & 3.4 & -33 \\
\hline 2.8 & 0.03 & 65 & 0.17 & 35 & & 0 \\
\hline 4.0 & 0.03 & 100 & & 0 & & 0 \\
\hline 5.1 & & 0 & & 0 & 96.4 & 100 \\
\hline
\end{tabular}

the best fit-the rate distribution of final relaxation for the lumps is very broad-but we believe that the Case III-R transport (modeled by Eq. (5)) is the most likely mechanism of the final relaxation $\left(\tau^{\prime \prime}=\eta / K \sim 13 \mathrm{~h}\right)$ at relatively low $\mathrm{CO}_{2}$ pressure. The Case II-R described by Eq. (4) was not clearly demonstrated as the exponential function seemed to be a slightly better fit in all instances except for the 4.1 MPa data for lumps. The 'tail' relaxation time constant had increased above pressure $4 \mathrm{MPa}$ up to $\sim 100 \mathrm{~h}$ (for both powder and lumps), which can be related to coal network relaxation caused by $\mathrm{CO}_{2}$ dissolution. This was preceded by apparent swelling of both powder and lumps at 2-3 MPa observed as negative increments in excess sorption (Romanov and Soong 2008). Despite the virtually identical rate constants of high-pressure relaxation process for helium (lumps $96 \mathrm{~h}$ and powder $75 \mathrm{~h}$ ) and for $\mathrm{CO}_{2}$ (lumps $95 \mathrm{~h}$ and powder $96 \mathrm{~h}$ ), the $\mathrm{CO}_{2}$ free-phase pressure relaxation is likely associated with changes in the void volume (Case IV-R); helium, on the other hand, penetrates rapidly into micropores $>0.42 \mathrm{~nm}$ at room temperature but it does not result in volumetric changes in coal structure at these pressures (Walker et al. 1988a; Romanov and Soong 2009).

The magnitude of the very slow coal swelling or shrinking could be linked to and convoluted by relatively faster gas transport. The negative slope of cumulative excess sorption as function of $\mathrm{CO}_{2}$ density, for relaxation during the first 1-2 min of each step, indicates that inaccessible volume of the lumps abruptly increased by $>2 \%$ at the $\mathrm{CO}_{2}$ pressure $\sim 4 \mathrm{MPa}$, corresponding to $\sim 2 \mathrm{mmol} /$ $\mathrm{mL} \mathrm{CO} 2$ density (Fig. 5). Swelling estimates based on the net negative (incremental) excess sorption numbers in Table 3 produce values of $\sim 3.3 \%$ for powder but only $\sim 1.3 \%$ for the lumps. The difference is attributed to internal swelling into the lump's macro- and meso-pores, which results in much slower diffusion and much larger relaxation times. In special circumstances, anomalies in the $\mathrm{CO}_{2}$ sorption-desorption behavior at free-phase densities 4-7 $\mathrm{mmol} / \mathrm{mL}$ can be explained by the competition between the distorted T-shaped $\mathrm{CO}_{2}-\mathrm{CO}_{2}$ clustering, typical of supercritical $\mathrm{CO}_{2}$ aggregation over the surface, and

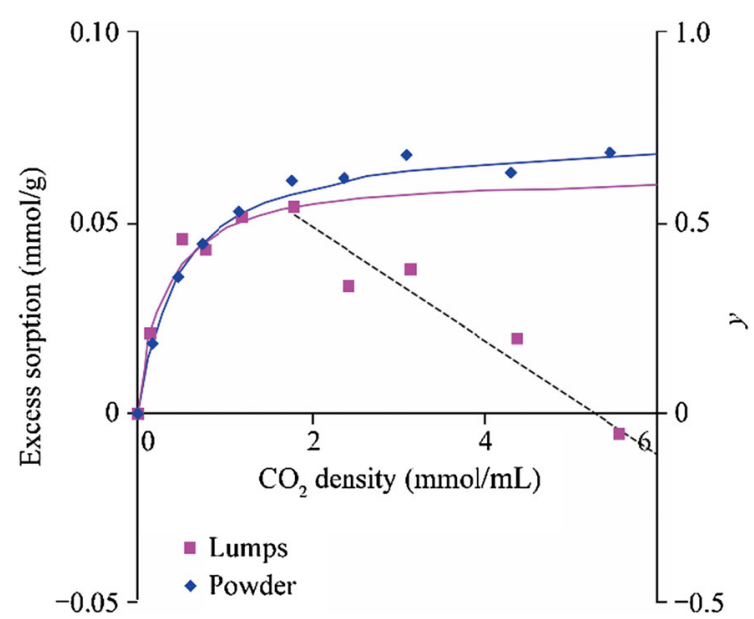

Fig. $5 \mathrm{CO}_{2}$ sorption at $55^{\circ} \mathrm{C}$ after the 'instant' (1-2 min) equilibrium (dry basis); left scale-lumps, right scale-powder. The solid lines represent the Langmuir fit for the low pressure data $(<4 \mathrm{MPa}$ or $<2 \mathrm{mmol} / \mathrm{mL}$ )

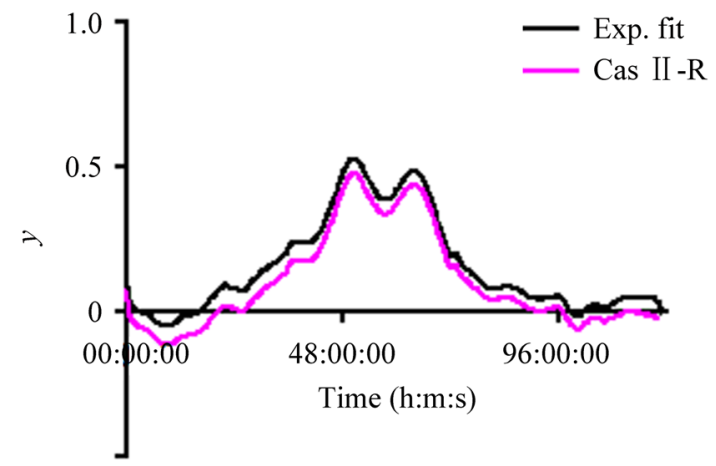

Fig. 6 The differences between the scaled 4.1 MPa pressure-step data for lumps $\left(\mathrm{CO}_{2}\right.$ sorption at $\left.55{ }^{\circ} \mathrm{C}\right)$ and the best fit functions (exponential and the Eq. (4))

the $\mathrm{CO}_{2}$ interaction energy $(\sim 0.2 \mathrm{eV})$ in 'free' phase (Schaef et al. 2014). However, in coal, similar to activated carbon, the linear negative slope and intercept of an excesssorption-versus-fluid-density plot are conventionally interpreted as measures of the adsorbed-phase volume and density respectively (Fitzgerald et al. 2003; Romanov and 
Table $4 \mathrm{CO}_{2}$ sorption kinetics on coal lumps

\begin{tabular}{|c|c|c|c|c|c|c|}
\hline \multirow[t]{2}{*}{ Pressure (MPa) } & \multicolumn{2}{|c|}{ Instant equilibrium } & \multicolumn{2}{|c|}{ Initial relaxation } & \multicolumn{2}{|c|}{ Final relaxation } \\
\hline & $\tau_{0}(\mathrm{~h})$ & Magnitude (\%) & $\tau_{i}(\mathrm{~h})$ & Magnitude (\%) & $\tau_{\mathrm{f}}(\mathrm{h})$ & Magnitude (\%) \\
\hline 0.3 & 0.03 & 6 & 0.13 & 29 & 14.52 & 65 \\
\hline 1.2 & 0.03 & 8 & 0.78 & 54 & 10.14 & 39 \\
\hline 1.9 & 0.03 & -6 & 0.51 & 73 & 14.26 & 33 \\
\hline 2.9 & 0.03 & 5 & 1.07 & 101 & 35.13 & -6 \\
\hline 4.1 & 0.03 & -1 & & 0 & 50.26 & 101 \\
\hline 5.2 & & 0 & 3.61 & 183 & 95.46 & -83 \\
\hline
\end{tabular}

Soong 2008). In lower-rank coals, the clay-especially, smectite (Romanov 2013)-contribution to $\mathrm{CO}_{2}$ sorption should not be ignored (Romanov et al. 2013; Santarosa et al. 2013); but the Upper Freeport coal's clay content is relatively low (Table 1) and despite the larger presence of minerals in the upper coal lump (as seen in Fig. $4 \mathrm{~b}$ and the top image in Fig. 2) their presence is not overwhelming.

Such discrepancy (for the lumps) can be attributed to Case II-R transport combined with swelling at $4.1 \mathrm{MPa}$ with the rate constant $\tau \sim 155 \mathrm{~h}$ (Eq. (4), best fit). In this case, Eq. (4) is a slightly better fit at the 'tail' of pressure relaxation (Fig. 6). Accounting for the magnitude of a 'bulge' in the 24-72 h time span (in the plot of experimental data minus best-fit function) would bring the swelling estimates up to $\sim 3.2 \%$ for the lumps (Table 4 ).

$\mathrm{Up}$ to $1.2 \mathrm{MPa}$, the best-fit adsorbed phase density ( $\sim 1.13 \mathrm{~g} / \mathrm{cm}^{3}$ ) corresponds to liquid (Romanov and Soong 2008). At 1.9 MPa, the amount sorbed is sufficient to fill up a half of the micropore volume or $1.9 \%$ of the total coal volume. At higher pressure, the best-fit adsorbed phase density $\left(>1.57 \mathrm{~g} / \mathrm{cm}^{3}\right)$ may reflect a transition to a solid phase (Walker 1981; Romanov and Soong 2008). At $>4 \mathrm{MPa}$, even the solid phase $\mathrm{CO}_{2}$ may fill $>1.7 \%$ of the coal volume, thus resulting in very strong interaction with individual chains of the macromolecular network of coal. Arguably, the subsequent relatively fast swelling was induced by $\mathrm{CO}_{2}$ dissolution in the coal matrix (Reucroft and Patel 1986; Walker et al. 1988a, b; Romanov and Soong 2008).

\section{Conclusions}

Transient sorption and desorption of helium and $\mathrm{CO}_{2}$ in Upper Freeport coal powder and lumps have been analyzed. Macroscopic and mesoscopic structural differences between powdered and non-powdered coal influence the contribution of three sorption steps (instant, initial and final relaxation) but not the characteristic rates of the gas transport kinetics and alteration of the coal texture (swelling, shrinkage, and changes in the pore structure and interconnectivity). Comparison of the multi-exponential relaxation time constants as a function of pressure, for $\mathrm{CO}_{2}$ $(<5.5 \mathrm{MPa})$ and helium $(<7 \mathrm{MPa})$, allows us to postulate several mechanisms responsible for observed pressure decay patterns.

Initially (at pressure $<2 \mathrm{MPa}$ ), diffusion is limited by mechanical response of the coal matter altering accessibility of the blind pores (Case III-R). The associated decrease in observed free-phase gas pressure follows on the heels of diffusion via interconnected pores (Case I-R). The time constant of such (elastic) rearrangement is independent of pressure $\left(\tau^{\prime \prime} \sim 13 \mathrm{~h}\right.$ for the Upper Freeport coal).

In the $\mathrm{CO}_{2}$ pressure range $2-5 \mathrm{MPa}$, the inaccessible coal matrix volume has increased by $2 \%-3.5 \%$. We attribute it to osmotically-induced strain relaxation (Case IV-R). At such pressures, the initial and final relaxation rates decreased, most likely due to sorption-induced pore blockage that forced a portion of $\mathrm{CO}_{2}$ transport to go through the coal matrix as dissolved species (Case II-R). The higher pressure relaxation rates $(\tau \leq 95 \mathrm{~h})$ are virtually independent of the gas nature $\left(\mathrm{CO}_{2} \mathrm{vs}\right.$. helium) and the coal particle size (lumps versus powder).

Acknowledgments The authors are grateful to T. Robert McLendon (NETL) and Bryan D. Tennant (AECOM) for assistance with CTscanning of the samples. Special thanks are given to Elizabeth Frommell (formerly NETL) for XRD analysis of the samples. This research was supported in part by an appointment to the U.S. Department of Energy (DOE) via Postgraduate Research Program at the National Energy Technology Laboratory administered by the Oak Ridge Institute for Science and Education under the RDS contract DE-AC26-04NT41817.

Disclaimer This project was funded by the Department of Energy, National Energy Technology Laboratory, an agency of the United States Government, through a support contract with AECOM. Neither the United States Government nor any agency thereof, nor any of their employees, nor AECOM, nor any of their employees, makes any warranty, expressed or implied, or assumes any legal liability or responsibility for the accuracy, completeness, or usefulness of any information, apparatus, product, or process disclosed, or represents that its use would not infringe privately owned rights. Reference herein to any specific commercial product, process, or service by trade name, trademark, manufacturer, or otherwise, does not necessarily constitute or imply its endorsement, recommendation, or favoring by the United States Government or any agency thereof. The views and opinions of authors expressed herein do not necessarily 
state or reflect those of the United States Government or any agency thereof.

Open Access This article is distributed under the terms of the Creative Commons Attribution 4.0 International License (http://crea tivecommons.org/licenses/by/4.0/), which permits unrestricted use, distribution, and reproduction in any medium, provided you give appropriate credit to the original author(s) and the source, provide a link to the Creative Commons license, and indicate if changes were made.

\section{Appendix}

In equilibrium, the flow gradient is balanced by the rate of dissolution of the extracted volatile matter (VM):

$\frac{\partial}{\partial r}\left(D \nabla c 4 \pi r^{2}\right)=4 \pi r^{2} \rho$

where $r$ is the distance from the center of the particle, $c$ is the concentration of extracted $\mathrm{VM}, \rho$ is the characteristic rate of dissolution, and $D$ is a diffusion coefficient.

The solution of this partial differential equation is:

$\nabla c=\left(\frac{\rho}{3 D}\right) r$

\section{References}

Alexeev AD, Vasilenko TA, Ulyanova EV (1999) Closed porosity in fossil coals. Fuel 78(6):635-638

Bhatia SK (1987) Modeling the Pore Structure of Coal. AIChE J 33(10): 1707-1718

Enderlein J, Erdmann R (1997) Fast fitting of multi-exponential decay curves. Opt Commun 134(1):371-378

Fitzgerald JE, Sudibandriyo M, Pan Z, Robinson RL Jr, Gasem KAM (2003) Modeling the adsorption of pure gases on coals with the SLD model. Carbon 41(12):2203-2216

Hall PJ, Thomas KM, Marsh H (1992) The relation between coal macromolecular structure and solvent diffusion mechanisms. Fuel 71(11):1271-1275

Hayashi J, Norinaga K, Kudo N, Chiba T (2001) Estimation of size and shape of pores in moist coal utilizing sorbed water as a molecular probe. Energy Fuels 15(4):903-909

Karacan C (2003) Heterogeneous sorption and swelling in a confined and stressed coal during $\mathrm{CO}_{2}$ injection. Energy Fuels 17(6): $1595-1608$

Karacan C (2007) Swelling-induced volumetric strains internal to a stressed coal associated with $\mathrm{CO}_{2}$ sorption. Int $\mathrm{J}$ Coal Geol 72(3-4):209-220

Li XC, Nie BS, Zhang RM, Chi LL (2012) Experiment of gas diffusion and its diffusion mechanism in coal. Int $\mathrm{J}$ Min Sci Technol 22(6):885-889

Mahajan OP (1991) $\mathrm{CO}_{2}$ surface area of coals: the 25-year paradox. Carbon 29(6):735-742

Marecka A, Mianowski A (1998) Kinetics of $\mathrm{CO}_{2}$ and $\mathrm{CH}_{4}$ sorption on high rank coal at ambient temperatures. Fuel 77(14): 1691-1696

Marzec A (2002) Towards an understanding of the coal structure: a review. Fuel Process Technol 77-78:25-32
Moffat D, Weale K (1955) Sorption by coal of methane at high pressures. Fuel 34:449-462

Nandi SP, Walker PJ (1970) Activated diffusion of methane in coal. Fuel 49(3):309-323

Nelson JR, Mahajan OP, Walker PJ (1980) Measurement of swelling of coals in organic liquids: a new approach. Fuel 59(12):831-837

Nie BS, He XQ, Li XC, Chen WX, Hu ST (2014a) Meso-structures evolution rules of coal fracture with the computerized tomography scanning method. Eng Failure Anal 41(Special issue on ICEFA V-Part II): 81-88

Nie BS, Hu ST, Li XC, Zhai SR (2014b) Experimental study of deformation rules during the process of gas adsorption and desorption in briquette coal. Int $\mathbf{J}$ Min Reclam Environ 28(5):277-286

Ozdemir E (2004) Chemistry of the adsorption of carbon dioxide by Argonne Premium Coals and a model to simulate $\mathrm{CO}_{2}$ sequestration in coal seams. Doctor's Thesis, University of Pittsburgh, Pittsburgh

Reeves S (2003) The Coal-Seq project: results of the allison and tiffany ECBM field studies. Alexandria, Virginia, s.n

Reucroft PJ, Patel H (1986) Gas-induced swelling in coal. Fuel 65(6):816-820

Romanov V (2007) Coal chemistry for mechanical engineers: from macromolecular thermodynamics to reservoir simulation. Energy Fuels 21(3):1646-1654

Romanov VN (2013) Evidence of irreversible $\mathrm{CO}_{2}$ intercalation in montmorillonite. Int J Greenhouse Gas Control 14:220-226

Romanov V, Soong Y (2008) Long-term $\mathrm{CO}_{2}$ sorption on upper freeport coal powder and lumps. Energy Fuels 22(2):1167-1169

Romanov V, Soong Y (2009) Helium-volume dynamics of Upper Freeport coal powder and lumps. Int J Coal Geol 77(Special Issue: $\mathrm{CO}_{2}$ Sequestration): $10-15$

Romanov VN, Goodman AL, Larsen JW (2006a) Errors in $\mathrm{CO}_{2}$ adsorption measurements caused by coal swelling. Energy Fuels 20(1):415-416

Romanov V, Soong Y, Schroeder K (2006b) Volumetric effects in coal sorption capacity measurements. Chem Eng Technol 29:368-374

Romanov VN, Ackman TE, Soong Y, Kleinmann RL (2009) $\mathrm{CO}_{2}$ storage in shallow underground and surface coal mines: challenges and opportunities. Environ Sci Technol 43(3):561-564

Romanov VN, Hur TB, Fazio JJ, Howarda BH, Irdi GA (2013) Comparison of high-pressure $\mathrm{CO}_{2}$ sorption isotherms on Central Appalachian and San Juan Basin coals. Int J Coal Geol 118:89-94

Ryan B, Mannhardt K (2007) Diffusivity and diffusion coefficients of anthracite. University of Alabama, Tuscaloosa, Alabama

Santarosa CS, Crandall D, Haljasmaa IV, Hur TB, Fazio JJ, Warzinski RP, Heemann R, Ketzerf JMM, Romanov VN (2013) $\mathrm{CO}_{2}$ sequestration potential of Charqueadas coal field in Brazil. Int J Coal Geol 106:25-34

Schaef HT, Glezakou VA, Owen AT, Ramprasad S, Martin PF, McGrail BP (2014) Surface condensation of $\mathrm{CO}_{2}$ onto kaolinite. Environ Sci Technol Lett 1(2):142-145

Siddiqui S, Khamees AA (2004) Dual-energy CT-scanning applications in rock characterization. SPE Paper 90520. Houston, Texas, s.n

Siemons N, Bruining H, Krooss B (2004) Upscaled diffusion in coal particles. Geol Belgica 7(3-4):129-135

van Krevelen D (1993) Coal. Elsevier, New York

Vorres K (1993) Users handbook for the argonne premium coal sample program, ANL/PCSP-93/1. Argonne National Laboratory, Lemont, Illinois

Walker PL (1981) Microporosity in coal: its characterization and its implications for coal utilization. Philos Trans R Soc Lond 300:65-81 
Walker PJ, Austin L, Nandi S (1966) Activated diffusion of gases in solids. Fuel (London) 45:173-175

Walker JPL, Verma SK, Rivera-Utrilla J, Davis A (1988a) Densities, porosities and surface areas of coal macerals as measured by their interaction with gases, vapours and liquids. Fuel 67(12):1615-1623

Walker JPL, Verma SK, Rivera-Utrilla J, Khan MR (1988b) A direct measurement of expansion on coals and macerals induced by carbon dioxide and methanol. Fuel 67(5):719-726
Wasaka S, Ibaragi S, Hashimoto T, Tsukui Y, Katsuyama T, Shidong S (2002) Study on coal liquefaction characteristics of Chinese coals. Fuel 81(11-12):1551-1557

Yang T, Nie BS, Yang D, Zhang RM, Zhao CH (2012) Experimental research on displacing coal bed methane with supercritical $\mathrm{CO}_{2}$. Saf Sci 50(4):899-902 